\title{
Formononetin ameliorates mast cell-mediated allergic inflammation via inhibition of histamine release and production of pro-inflammatory cytokines
}

\author{
NING XU ${ }^{1}$ and JUN AN ${ }^{2}$ \\ ${ }^{1}$ Department of Critical Care Medicine, Yulin Second Hospital, Yulin, Shaanxi 719000; \\ ${ }^{2}$ Department of Respiration, 3201 Hospital, Hanzhong, Shaanxi 723000, P.R. China
}

Received December 5, 2016; Accepted June 29, 2017

DOI: $10.3892 / \mathrm{etm} .2017 .5293$

\begin{abstract}
Various allergic diseases cause allergic inflammation, which is mediated by mast cells. The current study investigated the anti-allergic inflammatory effects of formononetin and its mechanism of action in vitro using mast cells. Levels of histamine and pro-inflammatory cytokines, including tumor necrosis factor- $\alpha$ (TNF- $\alpha$ ), interleukin (IL)-1 $\beta$ and IL-6, were measured to assess the effects of formononetin on allergic inflammation. The activation of intracellular calcium and nuclear factor (NF)- $\mathrm{kB}$, as well as the activity of caspase-1, were assessed to determine the mechanism of action. It was determined that difference concentrations of formononetin $(0.1,1$ and $10 \mu \mathrm{M})$ suppressed histamine release and secretion of TNF- $\alpha$, IL- $1 \beta$ and IL-6. Further investigations indicated that the effects of formononetin were associated with a reduction of intracellular calcium, suppression of NF- $\kappa \mathrm{B}$ activation and upstream IкK $\alpha$ phosphorylation and inhibition of caspase-1 activity. Therefore, the results of the current study demonstrated that formononetin ameliorated mast cell-mediated allergic inflammation.
\end{abstract}

\section{Introduction}

Allergic diseases, including asthma, atopic dermatitis, sinusitis, food allergies and anaphylaxis are induced by allergens and exhibit adaptive allergic inflammation. Mast cells are the effector cells during the mediation of allergic inflammation. Following exposure to external allergens, the cross-linking of immunoglobulin (Ig) E antibodies occurs and leads to aggregations of the IgE specific receptor (FceR), which binds to the surface of mast cells (1). Subsequently, histamine is

Correspondence to: Dr Jun An, Department of Respiration, 3201 Hospital, 783 Tianhan Road, Hanzhong, Shaanxi 723000, P.R. China

E-mail: anjun_007@163.com

Key words: formononetin, allergic inflammation, histamine, pro-inflammatory cytokines, nuclear factor- $\kappa \mathrm{B}$, caspase-1, intracellular calcium released and cytokines, chemokines, proteases and eicosanoids are secreted following the degranulation of mast cells (2). Histamine released from degranulated mast cells immediately initiates hypersensitivity and vasodilation and increases the permeability of vessels that have been exposed to external allergens (3). Pro-inflammatory cytokines secreted in mast cells, including tumor necrosis factor (TNF)- $\alpha$, interleukin (IL)-1 $\beta$ and IL-6 mediate the chronic inflammatory response (4).

Signaling in mast cells following allergic inflammation has been widely studied. Tyrosine-protein kinase Lyn and tyrosine-protein kinase Syk activated by the aggregation of FceR induce the phosphorylation of phosphoinositide 3-kinase (PI3K) and the phosphorylated PI3K stimulates protein kinase B (Akt) and phospholipase C (PLC) $\gamma$ (5). Subsequently, Akt and protein kinase $\mathrm{C}(\mathrm{PKC})$ phosphorylate the inhibitor of $\kappa B$ (IкB) kinase (IKK) (6). This phosphorylation of IKK stimulates the phosphorylation of nuclear factor (NF)- $\kappa \mathrm{B}$ inhibitor $\alpha(\mathrm{I} \kappa \mathrm{B} \alpha)$ and results in the degradation of $\mathrm{I} \kappa \mathrm{B} \alpha$ via the ubiquitin-proteasome pathway (7). NF- $\kappa \mathrm{B}$ bound to Iк $\mathrm{B} \alpha$, an important transcriptional factor in inflammation, is activated by phosphorylation following the degradation of I $\kappa \mathrm{B} \alpha$. Activated NF- $\kappa \mathrm{B}$ is translocated into the nucleus and regulates the expression of pro-inflammatory cytokine genes, including TNF- $\alpha$, IL-1 $\beta$ and IL- 6 , as well as the production of caspase-1 $(8,9)$. Caspase-1 is a member of the cysteine-aspartic acid protease (caspase) family and participates in the breakdown of proteins to produce aspartic acid residues. Activated caspase-1 induces inflammation by increasing the secretion of pro-inflammatory cytokines (10). In addition, $\mathrm{PLC} \gamma$ catalyzes the synthesis of inositol 1,4,5-trisphosphate (IP3). IP3 is usually bound to the receptors on the surface of the endoplasmic reticulum (ER) and stimulates the transient movement of calcium stored in the ER into the cytoplasm. The decrease in calcium concentration in the ER causes an immediate influx of calcium into the cell. Consequently, the intracellular calcium concentration increases, promoting the degradation of mast cells and the subsequent secretion of pro-inflammatory cytokines (11).

Formononetin is a natural isoflavone found in many medicinal plants, including Pongamia pinnata (12), Astragalus membranaceus (13), Ononis angustissima (14) and 
Trifolium pretense (15). Studies investigating formononetin have demonstrated that it upregulates nitric oxide synthase (16), inhibits angiogenesis and tumor growth (17) and induces the apoptosis of human osteosarcoma cells (18). Therefore, the present study investigated the anti-allergic inflammatory effects of formononetin and its mechanism of action.

\section{Materials and methods}

Reagents. Formononetin was supplied by Dalian Meilun Biology Technology Co., Ltd. (Dalian, China). Anti-dinitrophenyl (DNP) IgE, DNP-human serum albumin (HSA) and a total RNA purification kit were obtained from Sigma-Aldrich; Merck KGaA (Darmstadt, Germany). Dulbecco's modified Eagle's medium (DMEM) was purchased from Gibco; Thermo Fisher Scientific, Inc. (Waltham, MA, USA). Fluo-3/AM was purchased from the Beyotime Institute of Biotechnology (Nantong, China). The luciferase assay system was supplied by Promega Corporation (Madison, WI, USA). The Lipofectamine 2000 transfection reagent was obtained from Invitrogen; Thermo Fisher Scientific, Inc. and the caspase-1 fluorometric assay kit was supplied by AmyJet Scientific Inc. (Wuhan, China). ELISA kits for TNF- $\alpha$ (cat no. H052), IL-1 $\beta$ (cat no. H002), IL-4 (cat no. H005) and IL-6 (cat no. H007) were purchased from the Nanjing Jiancheng Bioengineering Institute (Nanjing, China).

Cell culture. RBL-2H3 cells were obtained from the Cell Bank of the Type Culture Collection of the Chinese Academy of Sciences (Shanghai, China). Cells were cultured in DMEM with $10 \%$ fetal bovine serum, $100 \mathrm{U} / \mathrm{ml}$ penicillin and $100 \mu \mathrm{g} / \mathrm{ml}$ streptomycin at $37^{\circ} \mathrm{C}$ in a humidified $5 \% \mathrm{CO}_{2}$ atmosphere. Cells were divided into a control group and experimental groups. The cells in experimental groups were sensitized with anti-DNP IgE $(10 \mu \mathrm{g} / \mathrm{ml})$ for $16 \mathrm{~h}$ and pretreated with concentrations of formononetin $(0,0.1,1$ and $10 \mu \mathrm{M})$ prior to treatment with of DNP-HSA $(500 \mathrm{ng} / \mathrm{ml})$. The cells in the control group were maintained in the normal aforementioned conditions.

Histamine release assay. The level of released histamine in the culture media was measured to assess the degranulation of mast cells, using the o-phthaldialdehyde spectrofluorometric method (19). RBL-2H3 cells (1x10\%/well) were sensitized with anti-DNP $\operatorname{IgE}(10 \mu \mathrm{g} / \mathrm{ml})$ and incubated overnight. Following pretreatment with or without formononetin $(0.1,1$ and $10 \mu \mathrm{M})$ for $30 \mathrm{~min}$ according to previous studies $(3,6)$, DNP-HSA $(500 \mathrm{ng} / \mathrm{ml})$ was added to the cells and they were incubated at $37^{\circ} \mathrm{C}$ for $2 \mathrm{~h}$. The cells were separated from the media by centrifugation at $400 \mathrm{x}$ g for $5 \mathrm{~min}$ at $4^{\circ} \mathrm{C}$. The fluorescence intensity was determined using a fluorescence plate reader and the excitation and emission wavelengths were set at 360 and $440 \mathrm{~nm}$, respectively.

Secretion of TNF- $\alpha, I L-1 \beta$ and $I L-6$. RBL-2H3 cells were treated as aforementioned and the supernatant was collected for analysis. TNF- $\alpha$, IL- $1 \beta$ and IL- 6 levels were determined using ELISA kits following the manufacturer's instructions. The absorbance of each sample was recorded on a microplate reader at $450 \mathrm{~nm}$. The results were expressed as $\mathrm{pg} / \mathrm{ml}$ derived from standard curves.

RNA extraction and reverse transcription polymerase chain reaction $(R T-P C R)$. Following stimulation with DNP-HSA in the presence or absence of formononetin, the total cellular RNA of RBL-2H3 cells was isolated using the total RNA purification kit following the manufacturer's protocol. The first strand cDNA was synthesized from $2 \mu \mathrm{g}$ total RNA using oligo (dT) primers. Following heating at $70^{\circ} \mathrm{C}$ for $5 \mathrm{~min}$ and the chilling on ice, the reaction system was mixed with avian myeloblastosis virus reverse transcriptase (AMV RT; Promega Corporation, Madison, WI, USA) together with 5X AMV RT reaction buffer and dNTP mix. The reaction system was then incubated at $42^{\circ} \mathrm{C}$ for $60 \mathrm{~min}$. PCR was performed to analyze the expression of TNF- $\alpha$, IL- $1 \beta$, IL- 6 and $\beta$-actin mRNA. The primer sets for the cytokines used were as follows: TNF- $\alpha$ forward, 5'-TCCCAAATGGGCTCCCTCTC-3' and reverse, 5'-AAATGGCAAACCGGCTGACG-3'; IL-1 $\beta$ forward, 5'-GCTGTGGCAGCTACCTATGTCTTG-3' and reverse, 5'-AGGTCGTCATCATCCCACGAG-3'; IL-6 forward, 5'-TGTGCAATGGCAATTCTGAT-3' and reverse, 5'-GAGCATTGGAAGTTGGGGTA-3', as outlined in a previous study (20). The amplified products were separated by electrophoresis with $2 \%$ agarose gel containing ethidium bromide and visualized on a Motic Images Advanced 3.2 imager system (Motic Incorporation, Ltd., Xiamen, China).

Level of intercellular calcium. The level of intracellular calcium was determined using Fluo-3/AM molecular fluorescence probes following the manufacturer's instructions. Briefly, $\mathrm{RBL}-2 \mathrm{H} 3$ cells were pre-incubated with Fluo-3/AM at $37^{\circ} \mathrm{C}$ for $1 \mathrm{~h}$ and the dye was then washed from the surface of cells. Cells were treated with or without formononetin at $37^{\circ} \mathrm{C}$ for $30 \mathrm{~min}$ prior to stimulation with DNP-HSA for $2 \mathrm{~h}$. The excitation and emission wavelengths were set at 488 and $525 \mathrm{~nm}$, respectively and measured using a fluorescence plate reader.

Protein extraction. The RBL-2H3 cells were pretreated prior to stimulation with DNP-HSA. Nuclear and cytosolic proteins were extracted, following a previously established protocol (17). Cells were lysed with ice-cold lysis buffer [10 mM HEPES/KOH, 2 mM MgCl $2,0.1 \mathrm{mM}$ EDTA, $10 \mathrm{mM}$ $\mathrm{KCl}, 1 \mathrm{mM}$ dithiolthreitol (DTT), $0.5 \mathrm{mM}$ phenylmethane sulfonyl fluoride (PMSF), $5 \mu \mathrm{g} / \mathrm{ml}$ leupeptin/aprotinin], left on ice for $5 \mathrm{~min}$, then vortexed and centrifuged at 1,200 $\mathrm{x} \mathrm{g}$ for $5 \mathrm{~min}$. The supernatant, which consisted of cytosolic proteins, was collected. Following washing with PBS, the pellets were suspended in another ice-cold buffer (50 mM HEPES/KOH, $50 \mathrm{mM} \mathrm{KCl}, 300 \mathrm{mM} \mathrm{NaCl}, 0.1 \mathrm{mM}$ EDTA, 10\% glycerol, $1 \mathrm{mM}$ DTT, $0.5 \mathrm{mM}$ PMSF, $5 \mu \mathrm{g} / \mathrm{ml}$ leupeptin/aprotinin) and incubated on ice for $20 \mathrm{~min}$. The solution containing nuclear protein was vortexed and centrifuged at $15,000 \mathrm{x}$ g for $5 \mathrm{~min}$ at $4^{\circ} \mathrm{C}$. The supernatant consisting of nuclear protein extracts was collected for analysis.

Western blot analysis. After determination of total protein using a BCA kit (A045-4; Nanjing Jiancheng Bioengineering Institute), the collected protein extracts were subjected to electrophoresis on $10 \%$ SDS-PAGE (50 $\mu \mathrm{g}$ protein per lane) 
and transferred to a nitrocellulose membrane. Membranes were then blocked with $5 \%$ nonfat milk for $1 \mathrm{~h}$ at room temperature. The expression of nuclear NF- $\kappa \mathrm{B}, \mathrm{I} \kappa \mathrm{B} \alpha$ and caspase-1 was detected using anti-NF- $\mathrm{B}$ (cat no. 3039), anti-IкB $\alpha$ (cat no. 9246) and anti-caspase-1 (cat no. 2225) antibodies (all 1:1,000; all from Cell Signaling Technology Inc., Danvers, MA, USA), which were incubated at $4^{\circ} \mathrm{C}$ overnight. The antibody of $\beta$-actin (1:1,000; cat no. 21338 ; Nanjing Jiancheng Bioengineering Institute) was used as the reference. The membranes were then incubated with horseradish peroxidase-conjugated secondary antibody $(1: 5,000$; cat no. 112-035-044; Jackson ImmunoResearch Laboratories Inc., West Grove, PA, USA) for $1 \mathrm{~h}$ at room temperature and an ECL kit (cat no. W028-1; Nanjing Jiancheng Bioengineering Institute) was used to visualize the immunoblots.

Cell transfection and dual-luciferase (firefly luciferase and Renilla luciferase) reporter assay for $N F-\kappa B$. RBL-2H3 cells $\left(1 \times 10^{6} /\right.$ well) were co-transfected with $100 \mathrm{ng} \mathrm{NF- \kappa B}$ luciferase reporter plasmid pGL4.32 and $9.6 \mathrm{ng}$ Renilla luciferase reporter vector plasmid pRL-TK per well (Promega Corporation, Madison, WI, USA). Transfection was performed over $24 \mathrm{~h}$ using Lipofectamine 2000 following the manufacturer's protocol. Medium was replaced with fresh serum-free medium. Cells were treated with or without formononetin prior to stimulation with DNP-HSA. Cells were then washed with ice-cold saline buffer and lysed with lysis buffer following the manufacturer's instructions. $20 \mathrm{~h}$ following transfection, luciferase activity was determined using the luciferase reporter assay system. Relative luciferase activity was determined by normalizing the firefly luciferase activity vs. the internal control Renilla luciferase.

Caspase-1 activity assay. Caspase-1 activity was measured using a fluorometric assay kit following the manufacturer's instructions. Cells were pretreated in the presence or absence of formononetin for $30 \mathrm{~min}$ prior to stimulation with DNP-HSA. Cells were then lysed and centrifuged at 10,000 x g for $1 \mathrm{~min}$ at room temperature. The supernatant was incubated with the fluorescence substrate YVAD-AFC at $37^{\circ} \mathrm{C}$ for $2 \mathrm{~h}$. Fluorescence intensity was measured on the fluorescence plate reader at an excitation wavelength of $400 \mathrm{~nm}$ and an emission wavelength $505 \mathrm{~nm}$.

Statistical analysis. Data are expressed as the mean \pm standard deviation. GraphPad Prism 5.0 (GraphPad Software, Inc., La Jolla, CA, USA) was used for statistical analysis. The experimental data from different groups were analyzed by one way analysis of variance followed by a Dunnett's t-test for multiple comparisons. Student's t-test was used for single comparisons. $\mathrm{P}<0.05$ was determined to indicate a statistically significant difference.

\section{Results}

Effect of formononetin on histamine release. The level of released histamine in the culture medium was determined to assess the extent of mast cell degranulation. Following stimulation with DNP-HSA, the release of histamine was significantly increased compared with the control group

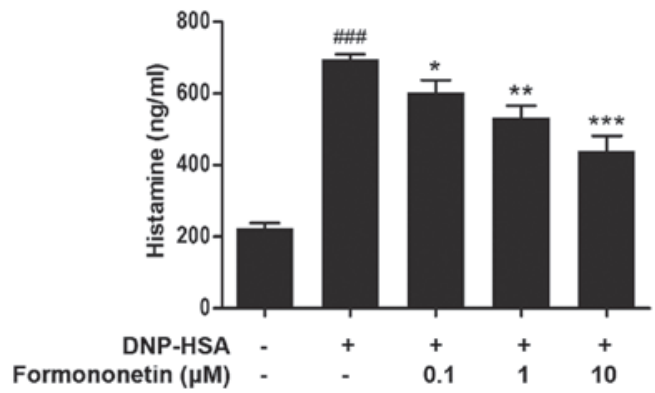

Figure 1. Effect of formononetin on histamine release in RBL-2H3 cells stimulated with DNP-HSA. Data are expressed as the mean \pm standard deviation. ${ }^{\# \# \#} \mathrm{P}<0.001$ vs. control group, ${ }^{*} \mathrm{P}<0.05,{ }^{* *} \mathrm{P}<0.01$ and ${ }^{* * * *} \mathrm{P}<0.001$ vs. DNP-HSA-stimulated group. DNP-HSA, anti-dinitrophenyl-human serum albumin.

$(\mathrm{P}<0.001$; Fig. 1). However, when pretreated with increasing doses of formononetin following stimulation with DNP-HSA, the level of released histamine was significantly decreased in a dose-dependent manner $(0.1 \mu \mathrm{m}, \mathrm{P}<0.05 ; 1 \mu \mathrm{m}, \mathrm{P}<0.01$; $10 \mu \mathrm{m}, \mathrm{P}<0.001$; Fig. 1).

Effect of formononetin on the secretion of pro-inflammatory cytokines. The expression of the pro-inflammatory cytokines TNF- $\alpha$, IL- $1 \beta$ and IL- 6 was determined to evaluate the effect of formononetin on inflammation (Fig. 2). The expression of TNF- $\alpha$, IL- $1 \beta$ and IL- 6 mRNA in RBL-2H3 cells stimulated by DNP-HSA was significantly increased compared with the control group (all $\mathrm{P}<0.001$; Fig. 2B-D). The expression of TNF- $\alpha$, IL- $1 \beta$ and IL- 6 mRNA in RBL-2H3 cells induced by DNP-HSA was significantly decreased in a dose-dependent manner following treatment with increased dosages of formononetin, compared with RBL-2H3 cells stimulated with DNP-HSA alone $(0.1 \mu \mathrm{M}, \mathrm{P}<0.05 ; 1 \mu \mathrm{M}, \mathrm{P}<0.01 ; 10 \mu \mathrm{M}$, $\mathrm{P}<0.001$; Fig. 2B-D).

Effect of formononetin on the level of intracellular calcium. The level of intracellular calcium was measured to investigate the mechanism of action of formononetin on the release of histamine. Following stimulation with DNP-HSA, the level of intracellular calcium was significantly increased compared with the control $(\mathrm{P}<0.001$; Fig. 3). By contrast, the level of intracellular calcium was significantly decreased following treatment with increasing doses of formononetin compared with the group treated with DNP-HSA alone $(0.1 \mu \mathrm{M}, \mathrm{P}<0.05$; 1 and $10 \mu \mathrm{M}$, both $\mathrm{P}<0.01$; Fig. 3).

Effect of formononetin on the activation of $N F-\kappa B$. Activated $\mathrm{NF}-\kappa \mathrm{B}$ serves an important role in the expression of pro-inflammatory cytokines. Thus, the effects of formononetin on the activation of NF- $\kappa \mathrm{B}$ and degradation of I $\kappa \mathrm{B} \alpha$ were determined. Levels of degraded I $\mathrm{B} \alpha$ were reduced in RBL-2H3 cells stimulated by DNP-HSA; however, they were increased following treatment with formononetin (Fig. 4A). By contrast, stimulation with DNP-HSA significantly induced the activation of NF- $\kappa$ B $(\mathrm{P}<0.001$; Fig. 4B), whereas treatment with formononetin inhibited the activation of $\mathrm{NF}-\kappa \mathrm{B}$ and significantly decreased the level of activated $\mathrm{NF}-\kappa \mathrm{B}$ in nuclei in a dose-dependent manner $(0.1 \mu \mathrm{M}, \mathrm{P}<0.05 ; 1$ and $10 \mu \mathrm{M}$, both $\mathrm{P}<0.001$; Fig. 4B). 

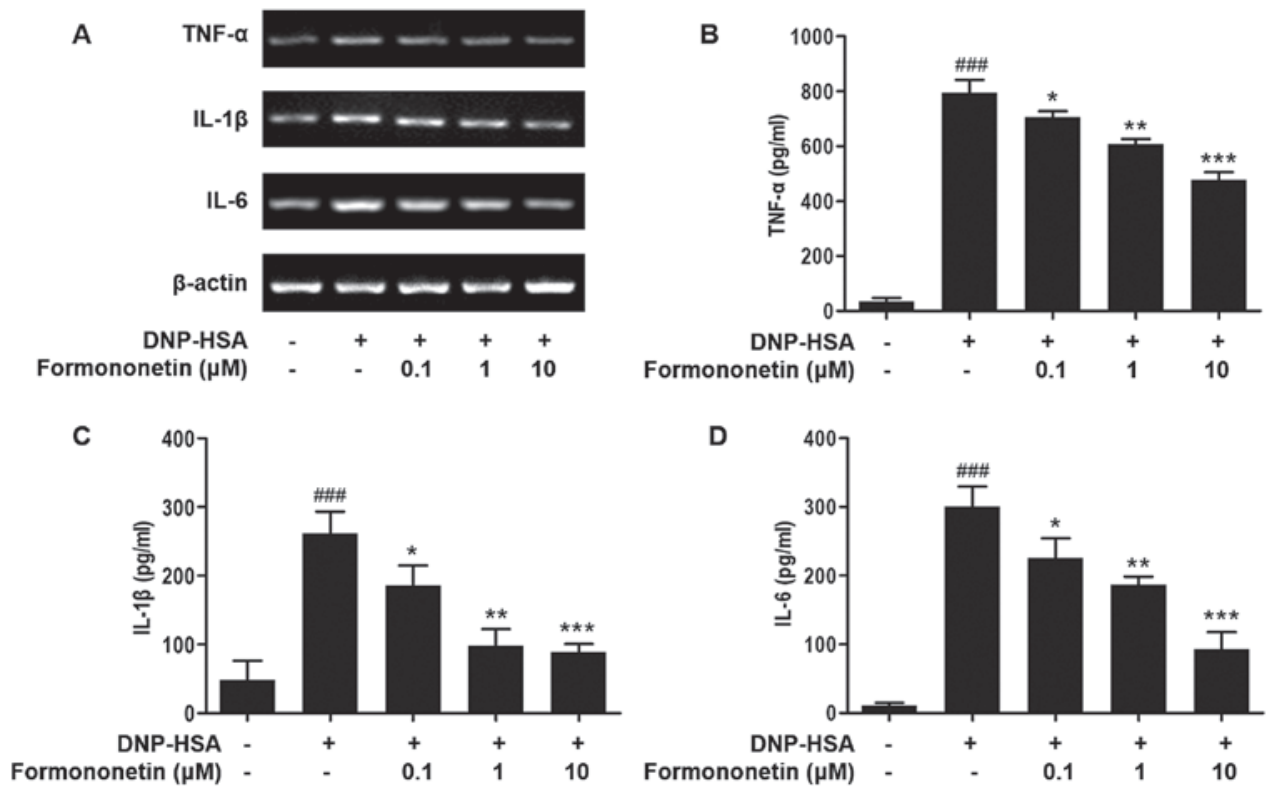

Figure 2. Inhibitory effects of formononetin on the secretion of TNF- $\alpha$, IL-1 $\beta$ and IL-6 in RBL-2H3 cells stimulated with DNP-HSA. (A) Reverse transcription-polymerase chain reaction products. (B) Expression of TNF- $\alpha$. (C) Expression of IL-1 $\beta$. (D) Expression of IL-6. Data are presented as the mean \pm standard deviation. ${ }^{* \# \#} \mathrm{P}<0.001$ vs. control group, ${ }^{*} \mathrm{P}<0.05,{ }^{* *} \mathrm{P}<0.01$ and ${ }^{* * *} \mathrm{P}<0.001$ vs. DNP-HSA-stimulated group. DNP-HSA, anti-dinitrophenyl-human serum albumin; TNF- $\alpha$, tumor necrosis factor- $\alpha$; IL, interleukin.



Figure 3. Effect of formononetin on intracellular calcium in RBL-2H3 cells stimulated with DNP-HSA. Data are presented as the mean \pm standard deviation. ${ }^{\# \#} \mathrm{P}<0.001$ vs. control group. ${ }^{*} \mathrm{P}<0.05$ and ${ }^{* *} \mathrm{P}<0.01$ vs. DNP-HSA-stimulated group. DNP-HSA, anti-dinitrophenyl-human serum albumin

Effect of formononetin on caspase-1 activity. Caspase-1 promotes the production of pro-inflammatory cytokines, thus, the activity of caspase-1 following treatment with formononetin was investigated to confirm the mechanism of anti-inflammation. Stimulation with DNP-HSA increased the expression (Fig. 5A) and significantly increased the activity of caspase-1 ( $\mathrm{P}<0.001$; Fig. 5B) compared with the control group. However, increasing doses of formononetin inhibited the expression (Fig. 5A) and significantly inhibited the activity ( $>1 \mu \mathrm{M}, \mathrm{P}<0.01$; Fig. $5 \mathrm{~B})$ of caspase- 1 in RBL-2H3 cells.

\section{Discussion}

Allergic inflammation is mediated by mast cells and causes allergic diseases. RBL-2H3 cells have been identified as a suitable cell line to conduct investigations into allergic inflammation in vitro (21). The current study investigated the anti-allergic inflammatory effects of formononetin and its
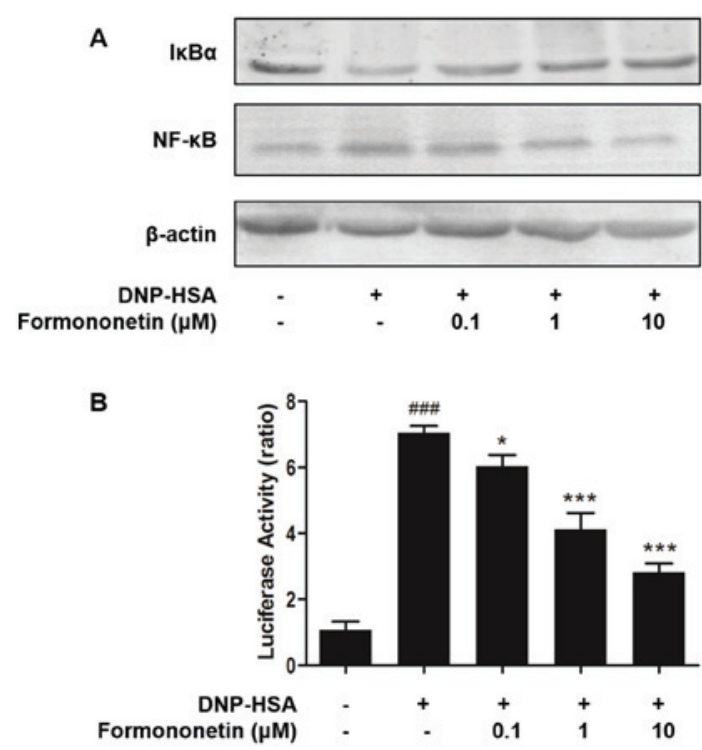

Figure 4. Formononetin inhibits the activation and translocation of NF- $\mathrm{BB}$ in RBL-2H3 cells stimulated with DNP-HSA. (A) Western blot analysis. (B) Luciferase activity assay. Data are presented as the mean \pm standard deviation. ${ }^{\# \# \#} \mathrm{P}<0.001$ vs. control group, ${ }^{*} \mathrm{P}<0.05$ and ${ }^{* * * *} \mathrm{P}<0.001$ vs. DNP-HSA-stimulated group. DNP-HSA, anti-dinitrophenyl-human serum

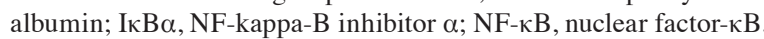

mechanism of action in mast cells. Histamine release serves an important role in the allergic reactions that occur following induction by external allergens and IgE-mediated signaling transduction. The level of released histamine indicates the extent of mast cell degranulation (4). Following treatment with formononetin, the increased level of released histamine in RBL-2H3 cells stimulated by DNP-HSA was reversed in a dose-dependent manner. These results indicate that formononetin treatment alleviates chronic allergic reactions. 

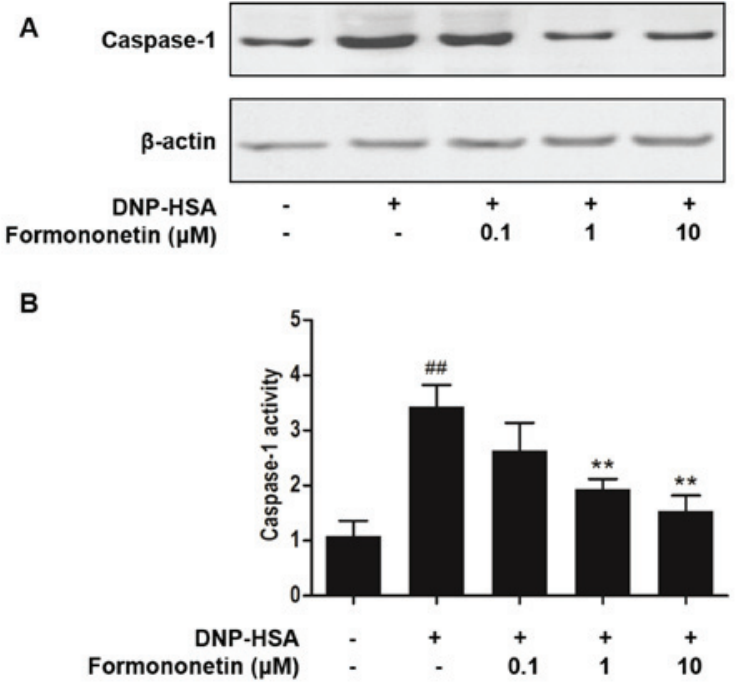

Figure 5. Formononetin inhibits the activity of caspase-1 in RBL-2H3 cells stimulated with DNP-HSA. (A) Western blot analysis. (B) Caspase-1 activity. Data are presented as the mean \pm standard deviation. ${ }^{\# \#} \mathrm{P}<0.01$ vs. control group. ${ }^{* *} \mathrm{P}<0.01$ vs. DNP-HSA-stimulated group. DNP-HSA, anti-dinitrophenyl-human serum albumin.

Intracellular calcium affects the release of histamine in mast cells and the expression of pro-inflammatory cytokines (22). Therefore, in the current study, the effect of formononetin on intracellular calcium was determined to investigate its mechanism of action in attenuating histamine release. The results demonstrated that formononetin decreased intracellular calcium levels, suggesting that formononetin decreases the level of released histamine by inhibiting intracellular calcium.

TNF- $\alpha$, IL- $1 \beta$ and IL- 6 are effective mediators of chronic inflammation (2). TNF- $\alpha$ mediates the inflammatory response in the early phase of an allergic reaction and IL-1 $\beta$ contributes to hypersensitivity and the inflammatory response (23). IL-6 is secreted in mast cells and is associated with acute allergic reactions and a chronic inflammatory response (21). Inhibiting the secretion of these pro-inflammatory cytokines improves inflammatory symptoms. The current study has revealed that formononetin significantly reduces the production of TNF- $\alpha$, IL- $1 \beta$ and IL- 6 in $\mathrm{RBL}-2 \mathrm{H} 3$ cells. In addition to intracellular calcium, $\mathrm{NF}-\kappa \mathrm{B}$ is a key transcription factor that influences the expression of these pro-inflammatory cytokines (8). The phosphorylation of $\mathrm{I} \kappa \mathrm{K} \alpha$ is essential in the activation and translocation of $\mathrm{NF}-\kappa \mathrm{B}$ (18). The results of the current study demonstrated that formononetin inhibits the activation and translocation of $\mathrm{NF}-\kappa \mathrm{B}$. It was also demonstrated that formononetin degrades I $\mathrm{K} \alpha$ via phosphorylation to produce free $\mathrm{NF}-\kappa \mathrm{B}$. These results suggest that the anti-inflammatory mechanism of action of formononetin is associated with the regulation of $\mathrm{NF}-\kappa \mathrm{B}$ and upstream I $\mathrm{K} \alpha$. This is consistent with the results of a previous study that demonstrated that treatment with formononetin in a dose-dependent manner regulates $\mathrm{NF}-\kappa \mathrm{B}$ activation in $16 \mathrm{HBE}$ cells (24).

Caspase-1 is a cysteine-aspartic acid protease that converts pro-cytokines into mature forms, such as IL-1 $\beta$ (25). Inhibition of caspase-1 activity attenuates inflammatory effects by reducing the secretion of related cytokines. The current study demonstrated that formononetin inhibits the activity of caspase-1 to attenuate inflammation. These results may contribute to further understanding regarding the anti-allergic inflammatory mechanism of formononetin.

In conclusion, the current study evaluated the effects and mechanism of action of formononetin on allergic inflammation in RBL-3H2 cells. Formononetin attenuates allergic reactions by reducing histamine release and the inflammatory response by inhibiting TNF- $\alpha$, IL-1 $\beta$ and IL-6 secretion. The mechanisms of this action include reducing intracellular calcium, inhibiting caspase- 1 activity and regulating the activation and translocation of NF- $\kappa \mathrm{B}$ and upstream phosphorylation of $\mathrm{I} \kappa \mathrm{K} \alpha$. Therefore, the current study demonstrated that formononetin prevents mast cell-mediated allergic inflammation.

\section{References}

1. Beghdadi W, Madjene LC, Benhamou M, Charles N, Gautier G, Launay P and Blank U: Mast cells as cellular sensors in inflammation and immunity. Front Immunol 2: 37, 2011.

2. Galli SJ and Tsai M: IgE and mast cells in allergic disease. Nat Med 18: 693-704, 2012.

3. Kim HH, Bae Y and Kim SH: Galangin attenuates mast cell-mediated allergic inflammation. Food Chem Toxicol 57: 209-216, 2013.

4. Galli SJ, Tsai M and Piliponsky AM: The development of allergic inflammation. Nature 454: 445-454, 2008.

5. Bansal G, Xie Z, Rao S, Nocka KH and Druey KM: Suppression of immunoglobulin E-mediated allergic responses by regulator of $\mathrm{G}$ protein signaling 13. Nat Immunol 9: 73-80, 2008.

6. Je IG, Kim DS, Kim SW, Lee S, Lee HS, Park EK, Khang D and Kim SH: Tyrosol suppresses allergic inflammation by inhibiting the activation of phosphoinositide 3-kinase in mast cells. PLoS One 10: e0129829, 2015.

7. Kalesnikoff J and Galli SJ: New developments in mast cell biology. Nat Immunol 9: 1215-1223, 2008.

8. Hayden MS and Ghosh S: NF-кB in immunobiology. Cell Res 21: 223-244, 2011

9. Lamkanfi M, Vande Walle L and Kanneganti TD: Deregulated inflammasome signaling in disease. Immunol Rev 243: 163-173, 2011.

10. Miao EA, Rajan JV and Aderem A: Caspase-1-induced pyroptotic cell death. Immunol Rev 243: 206-214, 2011.

11. Baba Y, Nishida K, Fujii Y, Hirano T, Hikida M and Kurosaki T: Essential function for the calcium sensor STIM1 in mast cell activation and anaphylactic responses. Nat Immunol 9: 81-88, 2008.

12. Li J, Jiang Z, Li X, Hou Y, Liu F, Li N, Liu X and Yang L: Natural therapeutic agents for neurodegenerative diseases from a traditional herbal medicine Pongamia pinnata (L.) Pierre. Bioorg Med Chem Lett 25: 53-58, 2015.

13. Li W, Sun YN, Yan XT, Yang SY, Kim S, Lee YM, Koh YS and Kim YH: Flavonoids from Astragalus membranaceus and their inhibitory effects on LPS-stimulated pro-inflammatory cytokine production in bone marrow-derived dendritic cells. Arch Pharm Res 37: 186-192, 2014.

14. Ghribi L, Waffo-Téguo P, Cluzet S, Marchal A, Marques J, Mérillon JM and Ben Jannet H: Isolation and structure elucidation of bioactive compounds from the roots of the Tunisian Ononis angustissima L. Bioorg Med Chem Lett 25: 3825-3830, 2015.

15. Tava A, Pecio Ł, Stochmal A and Pecetti L: Clovamide and flavonoids from leaves of Trifolium pratense and T. pratense subsp. nivale grown in Italy. Nat Prod Commun 10: 933-936, 2015.

16. Sun T, Cao L, Ping NN, Wu Y, Liu DZ and Cao YX: Formononetin upregulates nitric oxide synthase in arterial endothelium through estrogen receptors and MAPK pathways. J Pharm Pharmacol 68: 342-351, 2016.

17. Wu XY, Xu H, Wu ZF, Chen C, Liu JY, Wu GN, Yao XQ, Liu FK, Li $\mathrm{G}$ and Shen L: Formononetin, a novel FGFR2 inhibitor, potently inhibits angiogenesis and tumor growth in preclinical models. Oncotarget 6: 44563-44578, 2015. 
18. Hu W and Xiao Z: Formononetin induces apoptosis of human osteosarcoma cell line U2OS by regulating the expression of Bcl-2, Bax and MiR-375 in vitro and in vivo. Cell Physiol Biochem 37: 933-939, 2015.

19. Je IG, Kim HH, Park PH, Kwon TK, Seo SY, Shin TY and Kim SH: SG-HQ2 inhibits mast cell-mediated allergic inflammation through suppression of histamine release and pro-inflammatory cytokines. Exp Biol Med (Maywood) 240: 631-638, 2015.

20. Bae Y, Lee S and Kim SH: Chrysin suppresses mast cell-mediated allergic inflammation: Involvement of calcium, caspase-1 and nuclear factor- $\mathrm{KB}$. Toxicol Appl Pharmacol 254: 56-64, 2011.

21. Kim HH, Park SB, Lee S, Kwon TK, Shin TY, Park PH, Lee SH and Kim SH: Inhibitory effect of putranjivain A on allergic inflammation through suppression of mast cell activation. Toxicol Appl Pharmacol 274: 455-461, 2014.

22. Tanaka S, Mikura S, Hashimoto E, Sugimoto Y and Ichikawa A $\mathrm{Ca}^{2+}$ influx-mediated histamine synthesis and IL-6 release in mast cells activated by monomeric IgE. Eur J Immunol 35: 460-468, 2005.
23. Lee NY, Chung KS, Jin JS, Bang KS, Eom YJ, Hong CH, Nugroho A, Park HJ and An HJ: Effect of chicoric acid on mast cell-mediated allergic inflammation in vitro and in vivo. J Nat Prod 78: 2956-2962, 2015.

24. Shen D, Xie X, Zhu Z, Yu X, Liu H, Wang H, Fan H, Wang D, Jiang $\mathrm{G}$ and Hong $\mathrm{M}$ : Screening active components from Yu-ping-feng-san for regulating initiative key factors in allergic sensitization. PLoS One 9: e107279, 2014.

25. Besnard AG, Togbe D, Couillin I, Tan Z, Zheng SG, Erard F, Le Bert M, Quesniaux V and Ryffel B: Inflammasome-IL-1-Th17 response in allergic lung inflammation. J Mol Cell Biol 4: 3-10, 2012. 